Review

\title{
Review of the Charging Safety and Charging Safety Protection of Electric Vehicles
}

\author{
Linru Jiang *(D), Xiaohong Diao, Yuanxing Zhang, Jing Zhang and Taoyong Li \\ Department of Power Consumption \& Energy Efficiency (Beijing Engineering Technology Research Center of \\ Electric Vehicle Charging/Battery Swap), China Electric Power Research Institute, Beijing 100192, China; \\ Lucydxh@163.com (X.D.); zhangyuanxing1988@163.com (Y.Z.); opkl_5606@163.com (J.Z.); \\ taoyong_li@126.com (T.L.) \\ * Correspondence: jianglinru_epri@163.com
}

check for

updates

Citation: Jiang, L.; Diao, X.; Zhang,

Y.; Zhang, J.; Li, T. Review of the

Charging Safety and Charging Safety

Protection of Electric Vehicles. World

Electr. Veh. J. 2021, 12, 184. https://

doi.org/10.3390/wevj12040184

Academic Editor: Ghanim A. Putrus

Received: 12 August 2021

Accepted: 7 October 2021

Published: 12 October 2021

Publisher's Note: MDPI stays neutral with regard to jurisdictional claims in published maps and institutional affiliations.

Copyright: (c) 2021 by the authors. Licensee MDPI, Basel, Switzerland This article is an open access article distributed under the terms and conditions of the Creative Commons Attribution (CC BY) license (https:// creativecommons.org/licenses/by/ $4.0 /)$.

\begin{abstract}
With the continuous development of society and the economy and the popularization of the environmental protection concept, more and more people have begun to turn to electric vehicles. The application of electric vehicles can effectively avoid the damage caused by automobile fuel emissions to the surrounding environment and promote the development and utilization of new energy. However, the development of the electric vehicle industry has led to frequent accidents related to charging safety. In order to prevent accidents related to the charging safety of electric vehicles and ensure proper safety of passengers and people, the charging safety and charging safety protection methods of electric vehicles have become the research priorities for scholars. This paper reviewed the existing research results on the charging safety of electric vehicles, analyzed the influencing factors of the charging safety of electric vehicles, summarized the charging safety protection methods, and forecast the future research direction of charging safety, which has reference value and reference significance for the charging safety research of electric vehicles.
\end{abstract}

Keywords: electric vehicle; charging pile; charging process; safety protection

\section{Introduction}

In recent years, as the energy crisis and the ecological crisis intensify, people have begun to explore new means of transportation to replace traditional fuel vehicles [1]. The advent of electric vehicles (EV) provides effective solutions for energy conservation and environmental protection, becoming a research hotspot for academics and industrial circles $[2,3]$. The electric vehicle industry continues to thrive. The simulation results of the "EV30@30 model" released by the International Energy Agency shows that the global number of electric vehicles will rise to 240 million by 2030 [4]. Electric vehicles, the mainstream travel tool in the future, have their inherent and unique charging safety problems, which have aroused many interests and disputes [5,6].

On-board power batteries, the main source of power for electric vehicles, are extremely important to battery life. Compared with other types of on-board power batteries, the lithium-ion battery has the advantages of a long lifecycle, large single-cell energy density, high efficiency and no pollution; therefore, it is used on a large scale [7-9]. The on-board lithium-ion battery can be charged by conduction. The process of the energy supply system supplying energy to electric vehicles through charging piles, cables, charging guns and other components is known as conductive charging, which is the most widely used and energy-efficient charging mode [10]. In the process of conductive charging of electric vehicles, incidents such as elevated charging line temperature, short circuits in batteries or use of electric vehicles before finishing charging often occur. Spontaneous combustion and even explosion during the charging of electric vehicles, reported by news media, websites and newspapers, seriously threaten the personal safety of electric vehicle owners [11]. Frequent electric vehicle charging accidents have affected the sales and promotion of 
electric vehicles, and even restricted the development of the electric vehicle industry, and seriously deviated from the sustainable development strategy, a national key strategy [12]. Therefore, the safety of charging has gradually become a barrier to the promotion of the electric vehicle industry [13].

The standards $[14,15]$ for charging safety protection of batteries and charging equipment of electric vehicles have been formulated globally, including insulation [16], leakage [14], superheat [15], communication [17-23], and further research has been carried out on this basis. However, charging accidents of electric vehicles still occur frequently. How to effectively analyze the mechanism of various failures between batteries and charging equipment, and further establish a complete charging safety protection system is still a hot issue for scholars. Ouyang Minggao, an academician at Tsinghua University, points out that battery thermal runaway is the main reason for frequent charging accidents of electric vehicles, which restricts the development of the electric vehicle industry. Reference [10] also indicates that thermal runaway causes fires and explosions of electric vehicles during charging. The German ZSW Research Center, through experimental data analysis, shows that the lithium dendrites formed inside the battery during charging are the primary cause of battery thermal runaway [24]. In order to solve the thermal runaway caused by lithium dendrites, experts and scholars have conducted a lot of experimental simulation verification and proposed to improve the charging safety performance from two aspects. First, use the battery management system (BMS) to supervise the real-time battery status during charging $[25,26]$; second, analyze and simulate the failure cases that induce battery thermal runaway, reveal the growth essence of lithium dendrites, and then establish effective diagnosis schemes and early warning models to improve the charging safety performance of batteries $[27,28]$.

Charging piles, the most important supporting facility for charging, are attracting people's attention. In the charging process, the output voltage of a charging pile is up to several hundred volts. Any failure in the insulation or communication system of charging equipment may lead to charging accidents, even casualties. Reference [29], combined with relevant safety protection standards, summarizes the requirements and methods for insulation protection of charging piles and designs a three-layer safety protection system to improve the insulation protection level of charging equipment. Pile communication is another major feature of electric vehicles that is different from traditional fuel vehicles. The surge of electric vehicles will lead to increasingly frequent information interaction between electric vehicles and charging piles, which brings new challenges to the communication safety between electric vehicles and charging piles. Experts and scholars from various countries have conducted studies on the information safety in the charging process. Reference [30] expounds the importance of an embedded security system in the process of electric vehicle communication and analyzes the current challenges of charging pile communication safety and the future research direction. To ensure the privacy, controllability and completeness of data transmission between the charging pile and background service center, the authors of [31] designed a set of information safety protection schemes based on the background service center, which can effectively improve the safe operation environment of charging facilities and help to promote the development and application of supporting facilities for electric vehicles.

To sum up, experts and scholars have conducted many studies on charging safety and have achieved certain results. However, there are still gaps in the research on the influencing factors of charging safety and early warning and protection model, requiring in-depth discussion and improvement. This paper summarized the influencing factors of the charging safety of electric vehicles, summarized the technologies, methods and models of charging safety protection, presented the challenges and prospects of the future charging safety research in respect of improving the charging safety standard system, building a complete charging safety database, and improving the charging safety fault early warning mechanism, which has reference value and reference significance for further in-depth charging safety research of electric vehicles. 
The structure of this paper is categorized as follows: Section 2 summarizes the influencing factors of the charging safety of electric vehicles. Section 3 introduces the safety protection methods of battery and charging facilities. Based on the current development status, Section 4 presents some prospects for future development. Finally, Section 5 concludes the paper.

\section{Analysis of the Influencing Factors of the Charging Safety of Electric Vehicles}

The charging accidents of electric vehicles involve a wide range and various complex factors, which include damage to people, cars and surrounding facilities [26]. Research and analysis of influencing factors is the theoretical basis for studying the charging safety of electric vehicles.

As shown in Table 1, some published articles have reviewed the research on charging safety of electric vehicles. However, in fact, the charging safety of electric vehicles is closely related not only to the characteristics of the battery itself but also to the operating characteristics of charging facilities. Based on the existing review results, this paper takes the whole electric vehicle charging process as the research object and analyzes not only the relevant charging safety factors of electric vehicles but also the impact of charging facilities on charging safety.

Table 1. Review articles on charging safety of electric vehicles.

\begin{tabular}{|c|c|}
\hline Literature & Main Contributions \\
\hline$[32]$ & $\begin{array}{l}\text { Introduces the composition of BMS and the research status of key problems such } \\
\text { as voltage measurement and state estimation and puts forward the problems to be } \\
\text { solved in future research. }\end{array}$ \\
\hline [33] & $\begin{array}{c}\text { Summarizes the model-based and non-model-based fault diagnosis methods and } \\
\text { analyzes their advantages and disadvantages. }\end{array}$ \\
\hline [34] & $\begin{array}{l}\text { Reviews, classifies, and compares different adaptive mathematical models of deep } \\
\text { learning algorithms for residual service life prediction and provides suggestions } \\
\text { for improving the remaining battery life prediction algorithm. }\end{array}$ \\
\hline [35] & $\begin{array}{l}\text { Reviews SOC and SOH estimation technologies for electric vehicle batteries, and } \\
\text { specifically reviews model-based and data-driven methods for SOC estimation. }\end{array}$ \\
\hline [36] & $\begin{array}{l}\text { Reviews some battery cell balancing technologies and evaluates their relationship } \\
\text { with battery performance. }\end{array}$ \\
\hline
\end{tabular}

In order to effectively reduce the probability of charging accidents, this paper summarized the influencing factors of electric vehicle safety and charging pile safety, which are shown in Figure 1.

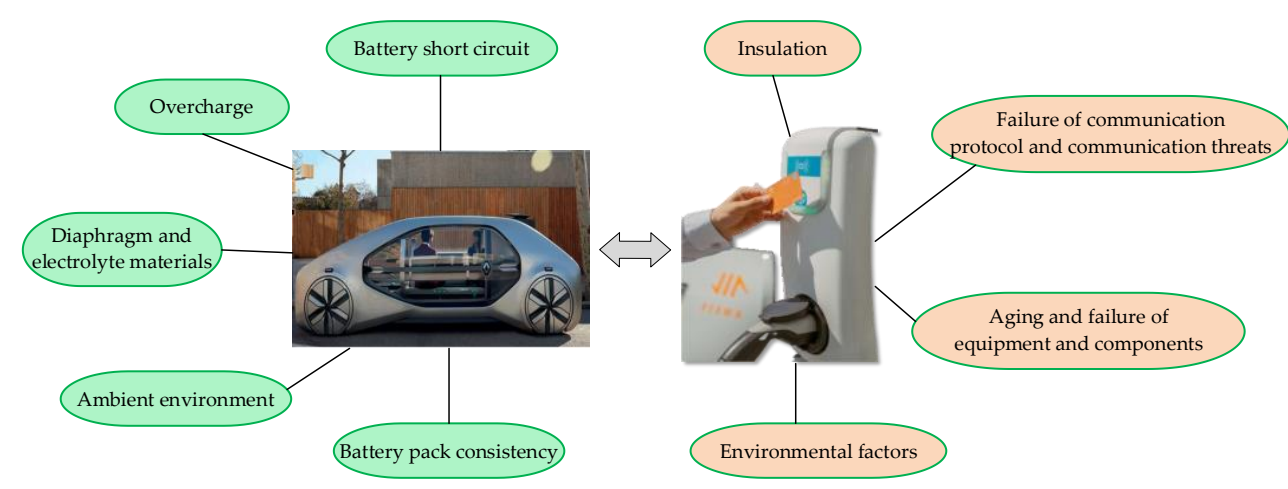

Figure 1. Influencing factors of electric vehicle safety and charging pile safety.

\subsection{Influencing Factors of Electric Vehicle Safety}

The state parameters of an on-board power battery can represent the advantages and disadvantages of electric vehicles and further reflect the safety performance of electric vehicles in the charging process $[37,38]$. An on-board power battery, the energy storage 
device for electric vehicles, is the main source of power for electric vehicles [39]. The battery performance is not only related to the daily range of electric vehicles but also affects the economic performance, safety performance and power performance of electric vehicles [40]. However, in recent years, the rising number of electric vehicle fires reported by media news has made the safety of electric vehicles the focus of attention. Figure 2 shows the statistics of electric vehicle fires worldwide from 2015 to 2019. It suggests an increasing proportion of electric vehicle fires during the charging process. Multiple electric vehicle fires occur every year around the world, which sometimes cause casualties. Table 2 presents the statistics of worldwide charging accidents of electric vehicles in recent years. It shows that the charging accidents caused by battery failure account for the main proportion. Therefore, the charging safety protection has become the primary problem in on-board power batteries.

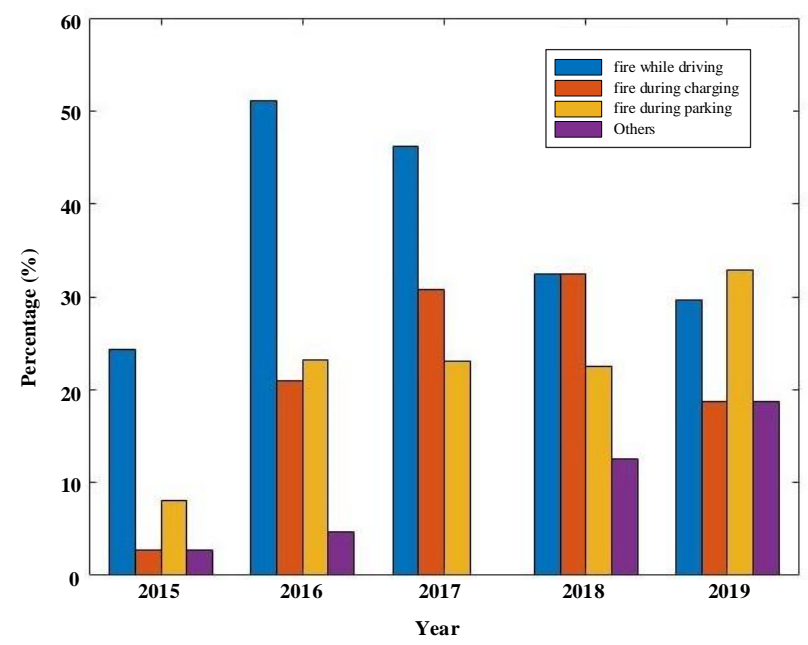

Figure 2. Statistics of worldwide electric vehicle fire status from 2015 to 2019.

Table 2. Statistics of worldwide charging accidents of electric vehicles in recent years (2015-2020).

\begin{tabular}{|c|c|c|c|c|}
\hline No. & Time & Place & Accident Description & Cause Analysis \\
\hline 1 & April 2015 & Shenzhen, China & $\begin{array}{l}\text { Smoke erupted from the battery of } \\
\text { an electric car, then it caught fire }\end{array}$ & $\begin{array}{l}\text { The electric car did not stop charging after } \\
\text { full charging, which caused overcharging for } \\
1.2 \mathrm{~h} \text {, causing a short circuit inside the battery }\end{array}$ \\
\hline 2 & January 2016 & Gjerstad, Norway & $\begin{array}{l}\text { A charging Tesla electric car in a } \\
\text { charging station burst into fire }\end{array}$ & $\begin{array}{c}\text { The battery was in low-temperature for a long } \\
\text { time and was charged in a high-rate charging } \\
\text { mode too long, resulting in thermal runaway } \\
\text { of the battery }\end{array}$ \\
\hline 3 & April 2019 & Shanghai, China & $\begin{array}{c}\text { A Tesla electric car suffered } \\
\text { spontaneous combustion while } \\
\text { charging }\end{array}$ & $\begin{array}{l}\text { The single battery failed, causing a short } \\
\text { circuit in the battery }\end{array}$ \\
\hline 4 & June 2019 & $\begin{array}{l}\text { Antwerp, } \\
\text { Northern Belgium }\end{array}$ & $\begin{array}{l}\text { A charging Tesla electric car } \\
\text { suddenly smoked, then caught fire } \\
\text { and was burned completely }\end{array}$ & A short circuit occurred during charging \\
\hline 5 & October 2019 & $\begin{array}{l}\text { Taegu, South } \\
\text { Korea }\end{array}$ & $\begin{array}{l}\text { A KONA electric car suddenly } \\
\text { caught fire while charging }\end{array}$ & $\begin{array}{l}\text { There were internal problems with the power } \\
\text { battery components }\end{array}$ \\
\hline 6 & May 2020 & Shaowu, China & $\begin{array}{l}\text { A VM electric car caught fire while } \\
\text { charging, and was burned }\end{array}$ & $\begin{array}{l}\text { The core supplier mixed impurities into cores, } \\
\text { so the power battery produced abnormal } \\
\text { lithium plating, causing a short circuit in the } \\
\text { battery }\end{array}$ \\
\hline 7 & May 2020 & Dongguan, China & $\begin{array}{c}\text { An electric car burst into fire while } \\
\text { charging }\end{array}$ & A charging fault occurred to the battery pack \\
\hline 8 & August 2020 & $\begin{array}{l}\text { Guangzhou, } \\
\text { China }\end{array}$ & $\begin{array}{c}\text { A short-circuit occurred to an } \\
\text { electric car in a charging station of } \\
\text { Wanjiang Bus Terminal }\end{array}$ & $\begin{array}{l}\text { Overcharging caused a short circuit in the } \\
\text { battery }\end{array}$ \\
\hline
\end{tabular}


The cut view of a battery is shown in Figure 3. A battery is mainly composed of positive and negative poles, the separator, tabs, the electrolyte and the pouch. With a complex working environment, the battery may experience mechanical damage, liquid immersion, overcharge, discharge, internal short circuit and other abuse scenarios during its whole life cycle [41], where its internal temperature may climb sharply. When the temperature rises to a certain range, decomposition of anode material, lithium insertion of cathode material, diaphragm melting, oxidation of electrolyte and then fierce burning inside the battery may happen, resulting in a sharp increase in battery temperature, i.e., thermal runaway [42-44]. By summarizing the journals, reports and standards of charging safety, this paper analyzed the influencing factors of the charging safety of electric vehicles, such as battery short circuit, overcharge, diaphragm and electrolyte materials, battery pack consistency, and ambient environment, and other influencing factors. Now, this paper will describe the features and action mechanisms of these influencing factors one by one.

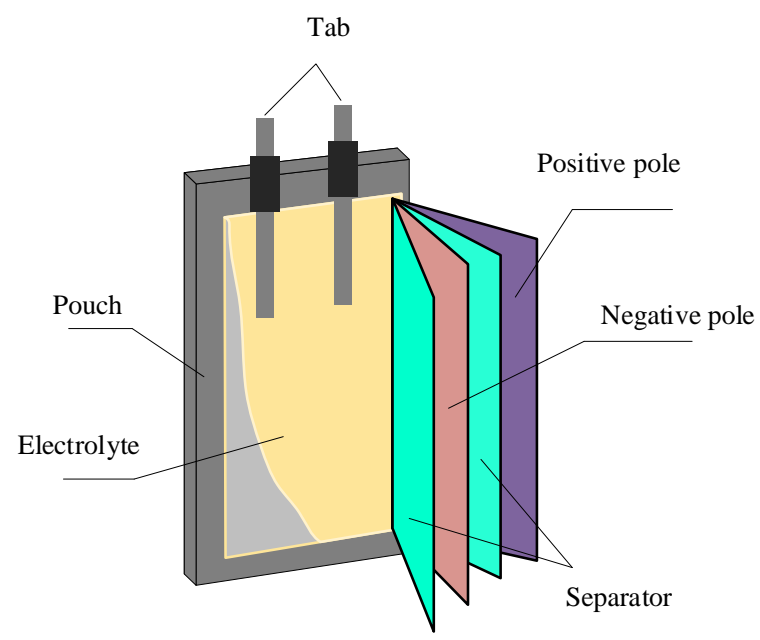

Figure 3. The cut view of a battery.

\subsubsection{Battery Short Circuit}

Battery short circuit, one of the electric abuse triggers, is also the most common cause of thermal runaway [45]. Lithium-ion batteries may be short circuited for multiple reasons, generating a large current in the battery in a short period of time, resulting in a sharp rise in battery temperature and then a charging accident [46]. There are three types of battery short circuits from the perspective of a trigger mechanism; namely, a battery short circuit caused by overcharge/discharge, a battery short circuit caused by mechanical damage, and a self-induced battery short circuit. Compared with the other two types of battery short circuits, the self-induced battery short circuit features strong latency and long action duration [47].

\subsubsection{Overcharge}

Battery overcharge is one of the important causes of thermal runaway [48,49]. During overcharging, the battery is powered continuously, making it a prolonged unsafe charging state, and even safety accidents. In addition, incorrect charging methods, excessive ambient temperature and uneven distributed polar coating cause battery overcharge [48]. The authors of [50], through test analysis, found that the risk of battery overcharge is strongly associated with the ambient temperature of the battery and the number of charging cycles.

\subsubsection{Diaphragm and Electrolyte}

The diaphragm, an important component of a battery, is aimed at separating the cathode from the anode to avoid battery short circuits. Battery safety is affected to some extent by the quality and performance of the diaphragm material. The uneven surface of the diaphragm material is likely to form lithium dendrites during the electrochemical 
reaction, which destroy the diaphragm material, causing a short circuit in the battery. In addition, long service time will lead to aging of the diaphragm, which may cause the battery to short circuit. Therefore, it is necessary to pay attention to the inspection and maintenance of the diaphragm during use. Reference [51] indicates that anode material, type of solvent, and external temperature will affect the solid electrolyte interface (SEI). It also points out that the risk of a battery short circuit can be reduced by selecting suitable materials and reasonably adjusting the product parameters in the production process.

Electrolyte, an important component of battery material, has a great impact on the performance of the battery [52]. During the whole life cycle of the battery, the electrolyte is subject to a degradation effect as the number of charges and discharges increases. Electrolyte, a combustible, easily produces gas in heat abuse and other bad cases, leading to expansion and even fierce burning of the battery.

\subsubsection{Battery Pack Consistency}

In the process of battery pack manufacturing, the different single battery manufacturing process directly affects the internal structure of battery, resulting in differences in parameters such as battery capacity, internal resistance and single battery voltage [53]. Even if the parameters of the battery pack are exactly the same when leaving the factory, the accumulative charging and discharging of electric vehicles will cause an internal attenuation effect in the battery pack, resulting in differences in a single battery [54,55]. For example, a single battery with large internal resistance is more difficult to fully charge than other single batteries, that is, the battery pack shows a "bucket effect" externally, making it difficult for the battery pack to reach the rated capacity [56]. In addition, the battery pack consistency also has some impact on its overcharging capacity. Some lithium-ion batteries, such as lithium iron phosphate batteries, are sensitive to overcharging. In order to ensure that all single batteries reach the full charge state, overcharge may occur in some single batteries, which may affect the life of a battery pack, and even threaten the safety of electric vehicles and supporting equipment [57].

\subsubsection{Ambient Environment}

The essence of common electric vehicle batteries is to transform chemical energy into electric energy, which affects the energy efficiency and safety of batteries in use. This chemical reaction is affected by the ambient environment. Therefore, in the process of charging, the impact of environmental factors on the safety of a battery cannot be ignored [58,59]. Reference [60] points out that as the charging environment becomes more complex, the impact of ambient temperature on the safety of a battery is more prominent. For example, when the ambient temperature is too low, too much lithium ions are embedded from the cathode and, after a while, deposited in the anode of the battery pack, causing a short circuit in batteries; when the ambient temperature is too high, the safety and stability of lithium battery cathode will be reduced. Therefore, effectively monitoring the ambient environment when charging will be conducive to protecting the charging safety and reduce the probability of charging accidents.

\subsubsection{Other Influencing Factors}

In addition to the factors mentioned above, battery type is another important factor affecting the safety of electric vehicles. There are many types of batteries used in electric vehicles, such as $\mathrm{LiFePO}$, $\mathrm{NiMH}, \mathrm{MnNiCo}$, et al. Due to the different performance of different batteries, their impact on the safety of electric vehicles is also different. For example, $\mathrm{MnNiCo}$ is easier to burn or even explode than $\mathrm{LiFePO} 4$ under destructive actions such as impact or puncture. Therefore, $\mathrm{MnNiCo}$ has higher requirements for anti-collision protection of the shell than $\mathrm{LiFePO}$. At the same time, the low-temperature resistance of $\mathrm{LiFePO} 4$ is not as good as that of $\mathrm{MnNiCo}$. Therefore, $\mathrm{LiFePO} 4$ needs low-temperature protection measures more than $\mathrm{MnNiCo}$. 
The charging safety performance of a battery is also affected by the battery charge and discharge ratios as well as the degree of self-discharge [61]. Furthermore, the safety of the battery pack is mainly guaranteed by accurate BMS control. In the daily charging process, the BMS ensures the charging safety of a battery by monitoring the parameters of a battery pack. Any mechanical failure of the BMS may threaten the charging safety of the battery [62].

\subsection{Influencing Factors of Charging Pile Safety}

Up to now, charging technology is no longer an important obstacle to the development of the electric vehicle industry. How to use effective methods to ensure the safe and stable operation of all kinds of equipment in the charging process has become increasingly important. In 2010 and 2013, the National Energy Administration officially released the NB/T33002-2010, NB/T33008.2-2013 and other standards, which give clear standards for the safety performance of charging piles during charging and regulate the test conditions, including insulation voltage resistance protection, environmental protection, lightning protection, and communication safety protection. Furthermore, the GB/T27930, a national standard, defines the equipment fault category during charging, which can be used to analyze the influencing factors of charging pile safety [63].

\subsubsection{Insulation}

To ensure personal safety during charging, good insulation protection is necessary for electrical equipment and lines [13]. The relevant sections in the GB/T18487.1-2015 clearly impose requirements on the structure and performance of charging piles [64]. In addition, the insulation design of charging piles can effectively provide a warning as to the failure of charging piles and other safety problems and then improve their safety. The insulation design of charging equipment includes insulation protection performance of the charging equipment shell, electrical clearance, creepage distance, dielectric strength, and insulation resistance. The following is the analysis of these elements.

First, the insulation protection performance of the charging equipment shell: The charging safety of charging piles is directly affected by the insulation protection performance of the charging equipment shell. The GB/T18487.1 clearly states that the insulation protection level of the charging equipment shell during charging can be represented as IPXXC [64], where $C$ means whether there is a danger to the user while using the equipment. It also specifies the charging safety protection of connectors in different states $[50,65]$. Second, electrical clearance and creepage distance: Electrical clearance refers to the shortest distance between two conductor components or between the conductor and an adjacent protective interface measured in the air while ensuring electrical performance and safety. Creepage distance refers to the shortest distance between electric chassis and connecting terminal or between two conductive components measured along the surface of the insulation material [66]. Third, dielectric strength: The greater the dielectric strength of the insulation material, the better the electrical resistance performance. The GB/T18487.1 sets up provisions and requirements for the insulation material properties of the charging equipment. In particular, the dielectric strength of the insulation material must meet the relevant standard [65]. Finally, insulation resistance: The GB/T 18487.1-2015 specifies that the insulation resistance between the circuits connected to the power supply equipment shall be equal to or greater than $10 \mathrm{M} \Omega$. In addition, to avoid electric shock accidents, protective measures shall be taken to overcome the air humidity change, aging, and moisture proofing of the insulation material of the charging equipment, so as to improve the insulation of the charging equipment [67].

\subsubsection{Failure of Communication Protocol and Communication Threats}

In the whole charging process, the reliability and safety of the communication system are of great significance to the safety of electric vehicles and supporting equipment such as charging piles $[13,65,68]$. When the communication protocol between the two is 
mismatched or incompatible, the electric vehicle will not be charged. In addition, any wrong message received or sent by either party will cause an interruption of charging or even spontaneous combustion of electric vehicles and charging equipment. At the end of the charging process, once the actual output voltage of the battery reaches the set voltage threshold, the BMS will send a signal to stop the charging [11]. Any failure of the BMS may lead to battery overcharge, even equipment fire or battery explosion, and thus burning of the charging pile. Thus, the GB/T27930-2015 stipulates that in any stage of the charging process (except special circumstances), the failure of receiving a message or incorrect format of a message from either party within $5 \mathrm{~s}$ shall be immediately determined as a communication timeout, and action shall be taken to ensure the safety of charging equipment.

In terms of communication safety, charging piles face various information safety threats, including natural elements and human elements, which show a changing trend over time [69]. Natural elements include all kinds of natural disasters, bad communication places, and equipment performance degradation, etc. Human elements include destruction, deception, and theft, etc., which bring economic losses to equipment operators [70]. For example, malicious network technology attacks interrupt the charging, tamper with the charging data in the charging process, affect the operator's revenue, and steal and leak the user's vehicle models and charging messages, causing user panic. Therefore, it is urgent to design the information safety protection scheme for charging piles, so as to improve the safety of information interaction in the charging process.

\subsubsection{Aging and Failure of Equipment and Components}

The aging failure of the equipment and components inside charging piles also affects the safety of charging piles in use. The charging pile in its whole life cycle will face high temperature, water logging, exposure to the sun, which accelerate the aging failure speed of the charging module, rectifier module, terminal equipment, leading to charging pile performance failure and charging accidents. This raises more stringent requirements for the necessity and timeliness of the operation and maintenance of charging equipment. Prolonged operating of the internal components of the charging pile at a high temperature, especially in summer, will cause irreversible damage to the lifetime of components and the insulation performance of cables, as well as thermal failure and aging of rectifier module [71]. Reference [67] points out that prolonged overheating of the DC contactor connecting terminal may cause oxidation and blackening of it, increased contact resistance, and even insulation aging or scorching of the wires connected to it, which seriously threaten the safety of charging equipment. Outdoor charging piles need to prevent water from entering the interior and metal parts of key modules inside them from becoming rust and aging, otherwise the safety risk in use will be increased.

\subsubsection{Environmental Factors}

Environmental factors such as weather, temperature and humidity have no negligible effect on the insulation performance of charging equipment, even the safety of charging equipment [72]. The safety of outdoor charging piles, especially when the charging station is not under a roof, is affected by environmental factors. Their internal system may fail due to a thunderstorm, high temperatures, or a typhoon in summer. For example, charging equipment in a thunderstorm is prone to a charged reaction that can generate high voltage, which damages high precision integrated circuits and a large number of microprocessors, ranging from damage to the electronic system inside the charging pile to burning of the internal lines of electric vehicles directly connected to the charging pile, thus leading to major accidents [73].

\subsubsection{Other Influencing Factors}

During the charging and operation of a charging pile, electricity quality is also an important factor affecting the safety and stability of the charging pile. The voltage fluctuation, 
electronic surge strike, or high harmonic in electric energy received by the charging station will affect the normal operation of the charging pile, causing the fault of the charging pile and even endangering the safety of the charging pile and electric vehicle equipment [67].

Moreover, the safety problems caused by safety function defects cannot be ignored. For example, interoperability function defects lead to a charging pile's failure to provide effective protection; an excessive output current of the charging pile can easily damage the structure of the electric vehicle battery system; insufficient IP protection levels of the system can easily cause a short circuit in the charging pile or even electric shock and other accidents to personnel [74]; in the case of emergency, the DC piles, due to no emergency stop device or their function failure, cannot cut off the interconnection between the piles in time and prevent the situation from deteriorating [75].

\section{Analysis of the Charging Safety Protection of Electric Vehicles}

Through the charging cycle, a charging accident will bring significant economic losses to the electric vehicle owners and system operators and will even cause casualties. Therefore, it is particularly important to timely and effectively provide early warnings of charging faults and take protective measures $[13,76]$.

\subsection{Charging Safety Protection of the Batteries of Electric Vehicles}

How to provide early warning, control the thermal runaway, and establish a comprehensive and effective battery safety protection system is an important technical difficulty to be solved urgently for the studying of charging safety of the batteries of electric vehicles $[77,78]$. Referring to the trigger and expansion mechanism of battery thermal runaway, in this paper, the charging safety protection technology of batteries were divided into the following parts: (1) internal short-circuit detection and protection technology; (2) battery overcharge mechanism analysis and diagnostic protection technology; (3) battery pack equalization technology; (4) development and application of highly stable battery materials; (5) battery status parameter monitoring and fault diagnosis method.

\subsubsection{Internal Short-Circuit Detection and Protection Technology}

Internal short-circuit is one of the important causes of accidents related to charging batteries. To timely and effectively detect the short-circuit in the battery during charging, researchers put forward internal short-circuit detection methods based on direct characteristics and indirect characteristics, respectively, to effectively prevent serious battery faults [46]. The internal short-circuit detection method based on direct characteristics analyzes the BMS sensing signal, and then analyzes the values and changes the rules of the battery voltage, current and temperature, so as to realize internal short-circuit detection. This method works depending on the comparison of the individual battery parameter threshold and the comparison of the group parameter change law. The steps are as follows: (1) Judge whether the sensing signal exceeds the fault threshold set by the system. For example, by simultaneously detecting the battery terminal voltage rise/drop rate and the temperature rise/drop rate, compare it with the parameter threshold set by the system, and then determine whether the battery has an internal short-circuit fault [27]. (2) Compare the change law of the sensing signal of each single battery in the battery pack, and then identify the abnormal individual battery: when a single battery in the battery pack is subject to an internal short-circuit, the voltage change law is quite different from that of the other single batteries. Thus, Xia Bing et al. [25] detect the battery short circuit by calculating the voltage correlation coefficient between single batteries. When the voltage correlation coefficient between a single battery and another battery experiences a sudden drop, an internal short-circuit occurs in the battery. The internal short-circuit detection based on direct characteristics is easy to operate and can realize the online detection of internal short-circuit in the battery. However, it cannot accurately detect the early signs of the internal short-circuit, and it is difficult to quantify the severity of the internal short-circuit. 
The internal short-circuit detection method based on indirect characteristics analyzes the relationship between the battery's internal short-circuit state and the equivalent resistance, self-discharge current and equivalent model parameters, makes the battery's internal short circuit detection equivalent to the parameter estimation, and then builds an equivalent model to realize internal short-circuit detection. Ouyang Minggao, an academician at Tsinghua University, and others carried out studies on the internal short-circuit in batteries [79-83]. The team proposed the fault diagnosis method based on the "averagedifference" model to detect internal short circuits in lithium-ion batteries. Experimental analysis shows that the method could correctly detect internal short-circuits at least $30 \mathrm{~min}$ before thermal runaway. In addition, SEO $\mathrm{M}$ et al. [84] put forward an internal short circuit-detection method based on the switching model method (SMM), which updates the parameters of an equivalent circuit model of battery short circuit, so as to more accurately estimate the open circuit voltage and charge state in the model and warn the internal-short circuit in batteries in advance. Reference [26] proposes a short circuit identification method through background data comparison, and a method that synchronously calibrates the BMS data transmission and estimates the internal resistance of a single battery, so as to identify the potential fault single battery. The above analyses show that the method based on indirect characteristics can provide the internal short-circuit detection results more accurately and quantitatively than the method based on direct characteristics, but it requires a complex modeling and testing process for batteries.

\subsubsection{Battery Overcharge Mechanism Analysis and Diagnostic Protection Technology}

In recent years, domestic and foreign research on lithium-ion battery overcharge safety, from aspects of overcharge mechanisms, protective materials, overcharge diagnosis and modeling, has never stopped. There is mature research on the fault mechanism of battery overcharge. For example, the team of Persis, a professor at the University of Orleans, carry out studies on battery overcharge $[85,86]$. The team revealed the internal reaction mechanism of battery overcharge by analyzing the overcharge behavior under different experimental conditions. Qi Chuang et al. [87] reveal the influence mechanism between the overcharge flow of different rates and the battery stability using the multiphysical field coupling model. Lin Chengtao et al. [88] analyze the thermal phenomenon during the overcharge of such batteries from different angles using the electric-thermal coupling model of an LMO lithium-ion battery. The experimental results show that the side effects are the main hidden danger of lithium-ion battery overcharge. Therefore, measures should be taken to avoid the risk of thermal runaway caused by the overcharge side effects.

The development of new overcharge protection material is a simple and economical method that can simplify the production process and reduce the risk of overcharge from the root. The overcharge protection studies by Wang Qingsong's team, a team in the National Key Laboratory of Fire Science at the University of Science and Technology of China, show that PCM materials with low melting index have superior cooling performance, which helps to reduce the risk of thermal runaway probability [89,90]. Apart from this, the construction of an overcharge diagnosis model is the focus of studying overcharge protection. Reference [91] studies the possible overcharge fault in the charging process of lithium-ion batteries and verifies that the proposed method can accurately diagnose overcharge faults using the second-order resistance capacity model of lithium batteries. The above overcharge protection research is mature for lithium-ion batteries with general specifications and performance but not for the new lithium-ion batteries in the market, so it is urgent to further improve the overcharge protection research of lithium-ion batteries [92].

\subsubsection{Battery Pack Equalization Technology}

The on-board power battery consists of multiple single batteries in series to meet the daily driving needs of electric vehicle owners. Affected by the production process, battery aging and ambient temperature, the rated voltage, capacity, internal resistance inevitably differ, which accumulates and expands over time. Battery pack equalization technology, an 
important method to solve the problem of battery pack consistency, plays a negligible role in the use of single batteries in groups. Different battery pack equalization methods have been proposed by scholars [93]. See Table 3 below for details.

Table 3. Comparison of various battery pack equalization methods.

\begin{tabular}{|c|c|c|c|}
\hline Method & Literature & Advantages and Disadvantages & $\begin{array}{c}\text { Equalization Circuit } \\
\text { Diagram }\end{array}$ \\
\hline $\begin{array}{l}\text { Dissipative } \\
\text { shunt } \\
\text { equalization } \\
\text { method }\end{array}$ & {$[94]$} & $\begin{array}{l}\text { Advantages: low energy consumption, strong scalability, } \\
\text { easy for modular design. } \\
\text { Disadvantages: thermal management problems and only } \\
\text { for small-power battery packs. }\end{array}$ & See Appendix A Figure A1 \\
\hline $\begin{array}{l}\text { Complete } \\
\text { shunt } \\
\text { equalization } \\
\text { method }\end{array}$ & [95] & $\begin{array}{l}\text { Advantages: large equalization current and fast } \\
\text { equalization speed. } \\
\text { Disadvantages: high cost and strict variation range of } \\
\text { charger output voltage. }\end{array}$ & See Appendix A Figure A2 \\
\hline $\begin{array}{l}\text { Isomorphic CE } \\
\text { equalization } \\
\text { method }\end{array}$ & [96] & $\begin{array}{c}\text { Advantages: can achieve the non-destructive balance } \\
\text { between charge energy and discharge energy of battery } \\
\text { pack. } \\
\text { Disadvantages: strict requirements for battery voltage } \\
\text { monitoring technology and complicated equalization } \\
\text { circuit structure. }\end{array}$ & See Appendix A Figure A3 \\
\hline $\begin{array}{l}\text { Multiswitching } \\
\text { capacitance } \\
\text { method }\end{array}$ & [97] & $\begin{array}{c}\text { Advantages: low requirements for the intelligence of } \\
\text { control system, and simple circuit structure. } \\
\text { Disadvantages: low sensitivity to voltage and low } \\
\text { equilibrium accuracy. }\end{array}$ & See Appendix A Figure A4 \\
\hline $\begin{array}{l}\text { Single } \\
\text { switching } \\
\text { capacitance } \\
\text { method }\end{array}$ & [98] & $\begin{array}{l}\text { Advantages: only need a switching capacitance, good } \\
\text { economy. } \\
\text { Disadvantages: the equilibrium cycle is limited by the } \\
\text { number of single batteries, slow equalization speed. }\end{array}$ & See Appendix A Figure A5 \\
\hline $\begin{array}{l}\text { Multi-winding } \\
\text { transformer } \\
\text { method }\end{array}$ & [99] & $\begin{array}{l}\text { Advantages: high efficiency and no closed-loop control } \\
\text { and voltage monitoring equipment. } \\
\text { Disadvantages: weak scalability, general tailor ability, } \\
\text { difficult design of a multi-winding transformer. }\end{array}$ & See Appendix A Figure A6 \\
\hline $\begin{array}{l}\text { Switching } \\
\text { transformer } \\
\text { method }\end{array}$ & [98] & $\begin{array}{l}\text { Advantages: low cost, low circuit design difficulty. } \\
\text { Disadvantages: large circuit loss, low equalization } \\
\text { efficiency. }\end{array}$ & See Appendix A Figure A7 \\
\hline
\end{tabular}

\subsubsection{Development and Application of High Stable Battery Materials}

Battery materials are closely related to battery safety, so the battery safety during charging can be improved by the development of highly stable battery materials [38]. Lithium-ion batteries are generally composed of a cathode, anode, electrolyte, and diaphragm, etc. The thermal runaway characteristics of lithium-ion batteries are improved by upgrading the cathode and anode [100-102], diaphragm [103] and electrolyte [104,105], which can fundamentally prevent the thermal runaway. The modification of electrode materials includes surface coating and doping modification [100,101], while the improvement [106] of the electrolyte includes the development of new lithium salt, solvent modification and addition of electrolyte flame retardant, so as to improve the safety of electrolyte. For example, Zeng Ziqi et al. [107] synthesize a new TFMP as a flame retardant, reducing the combustibility of the electrolyte and having less impact on the electrochemical properties of the battery.

The diaphragm is a key safety component of a lithium-ion battery. The development of high-strength inorganic diaphragm material can effectively improve the puncture resistance of a diaphragm and also enhance the thermal stability of a lithium-ion battery [108]. 
For example, the literature [109] compounds ceramic particles on the surface of the battery diaphragm to prepare a composite diaphragm. The simulation results show that the use of this composite can effectively reduce the high-temperature thermal contraction of the diaphragm and improve the charging safety of the battery. In addition, the development of hard-burning all-solid-state batteries will help to solve the thermal runaway problem of the lithium-ion battery from the root [110]. However, the simulation test data on the thermal runaway and thermal diffusion of all-solid-state lithium battery is scarce, and some parameters are not clear. Whether they can fundamentally solve the intrinsic safety problem of lithium-ion batteries still needs to be further studied [111].

\subsubsection{Battery Status Parameter Monitoring and Fault Diagnosis Method}

The BMS plays the most critical role in charging safety [12]. The monitoring device and signal collection device in the BMS can monitor and collect parameters of input current, input voltage, and charge state of the battery in real-time when charging, so as to keep the battery in a normal operating state [43]. Reference [32] introduces the composition of BMS and the research status of key problems such as voltage measurement and state estimation and puts forward the problems to be solved in future research. In addition to this, the battery fault diagnosis method needs to be upgraded and improved. Xiong Jing et al. [38] analyze the fault diagnosis and detection method of a lithium-ion battery based on coordinated probability and signal monitoring, pointing out that the method is too dependent on the thermal characteristics of a battery. Xiao Yao [28], a student at UESTC, provides BMS with a fault real-time online analysis system with functions of fault analysis, early warning, and processing, which can dynamically monitor the state of a lithium-ion battery in real-time, analyze the abnormal situation online, and immediately terminate charging for subsequent processing for any internal fault of the battery. The aging of lithium-ion batteries and the relationship between performance and failure are quantitatively analyzed in the literature [112]. This paper summarizes the model-based and non-model-based fault diagnosis methods and analyzes their advantages and disadvantages. It is suggested that the combination of methods can be used to improve the fault diagnosis process.

\subsection{Charging Safety Protection of the Charging Equipment of Electric Vehicles}

Charging equipment, an important supporting facility of electric vehicles, has complex structures and functions [113]. Any failure of key modules such as insulation detection and communication in the system will endanger the safety of personnel and equipment. Therefore, to effectively protect the safety of electric vehicle charging equipment, measures should be taken to ensure its health state in the charging process.

\subsubsection{Insulation Protection Technology of Charging Equipment}

During charging, the voltage between an electric vehicle and charging pile is up to several hundred volts. Once the equipment insulation fails, it will seriously endanger the safety of personnel [114]. With respect to insulation protection for electric vehicle charging equipment $[115,116]$, basic safety protection assessment standards for charging equipment have been issued globally, and significant exploration and testing has been conducted with these standards as a benchmark. For example, the Electric Vehicle Association in Germany carried out a study on the DC leakage protection, charging cable self-inspection and other technologies of charging piles [112,117]. Reference [118] eliminates the insulation fault by using the charging pile added with a detection main control module to conduct insulation self-inspection on the charging pile before charging. Reference [29] takes protective measures for direct and indirect electric shock protection to improve the insulation protection level of charging piles. Direct electric shock protection is to insulate the parts of charging piles with which consumers may contact, so as to protect the personal safety of consumers. When the dangerous charged body is exposed, the charging pile has chaotic output current 
or even cannot be charged, the indirect electric shock protection system will cut off the power supply and terminate the charging to ensure the personal safety of consumers.

The charging pile shall be directly connected to the electric vehicle when working. Therefore, the charging pile should not only improve its own insulation protection ability but also carry out real-time detection of the electric vehicle. Once the battery insulation is damaged, it should immediately turn off the power supply and stop the charging [119]. Guo Hongyu et al. [120] put forward an insulation detection method of injecting high pressure into the detection device through the isolation transformer, which ensures the real-time capability and accuracy of insulation detection. To solve the current insulation detection problems of battery electric vehicle batteries, Zhang Xiangwen et al. [121] designed a new electric bridge insulation detection system. The system is simple to operate, with high accuracy, and the measurement error is less than $5 \%$ due to numerous experiments.

\subsubsection{Communication Safety Protection Technology of Charging Piles}

The charging pile integrating the control system and the information network has a large number of information security threats, which may have a certain impact on user privacy, charging pile operation company's income, and power system stability [31]. In order to establish an open communication standard, The Open Charging Protocol (OCPP) was developed by the Open Charging Alliance (OCA). This protocol allows charging stations (CS) and charging management systems (CSMS) of different manufacturers to communicate with each other. OCPP exists in different versions $(1.2,1.5,1.6,2.0)$. The wide usage of version 1.5 and 1.6 of OCPP made it a global standard [122]. Based on the ISO/ICE 15118 , Reference [123] analyzes the potential safety risks of vehicle pile communication messages, points out the potential problems in data privacy, completeness, and practicality, and designs a variety of measures to correct them.

Figure 4 is the communication structure diagram of a charging pile now in use. The background main station system of a charging pile controller uses CAN bus or GPRS, a wireless public network, as the communication network of the charging pile. In this system, the communication line is not completely isolated from other users, so hackers can use techniques such as eavesdropping, monitoring, or decoding to obtain information. Therefore, the security of the system is low. Reference [31] points out that the information security threats of charging pile are theft, tampering and forgery and analyzes the protective measures that can be taken in different security demand scenarios, such as communication encryption, personnel identity authentication, information integrity verification, etc. Reference [124] points out the importance of information security when the charging pile transmits communication data through GPRS and puts forward the communication security strategy of the charging pile while meeting the requirements of cost and reliability of charging piles and other infrastructure. To deal with the illegal tampering of data in the process of vehicle pile communication, Reference [125] designs a new connection device to ensure the confidentiality and integrity of data transmission, making the charging services of the charging pile for electric vehicles safer and more reliable. To sum up, the previous research on data interaction safety between a charging pile and a single subject rather than multiple subjects is mature.

\subsubsection{Aging Prediction and Protection Technology of Charging Piles}

After the charging equipment is put into operation, it is difficult to detect the equipment aging and line damage without regularly testing their health status, which increases the safety risk in the use of the charging pile. Thus, analyzing the aging mechanism of key modules and predicting the aging curve of equipment can effectively improve the safety and service life of equipment, which is of great significance to the safety of charging equipment, electric vehicles and people [126]. Reference [71] analyzes the aging mechanism of the charging pile and designs an aging test system of the DC charging pile based on the $\mu \mathrm{C} / \mathrm{OS}-\mathrm{II}$ system. The system can effectively test and select the qualified DC charging pile during the daily operation and maintenance process, which improves the long-term 
reliability and safety of the overall unit. Zhang Han et al. see the health evaluation, bad working condition evaluation and aging maintenance evaluation as the basic elements of the health state evaluation of a charging pile and predict the health state of a charging pile based on a Markov prediction model. The simulation results show that the model can predict the aging curve of elements inside the charging pile accurately, improve the timeliness of later operation and maintenance of the charging pile, and effectively guarantee the health state of the charging pile [127]. In addition, the status monitoring frequency and status identification accuracy of equipment inside the charging pile should be improved, and regular inspection and maintenance efforts should be strengthened, so as to reduce the probability of risk caused by aging.

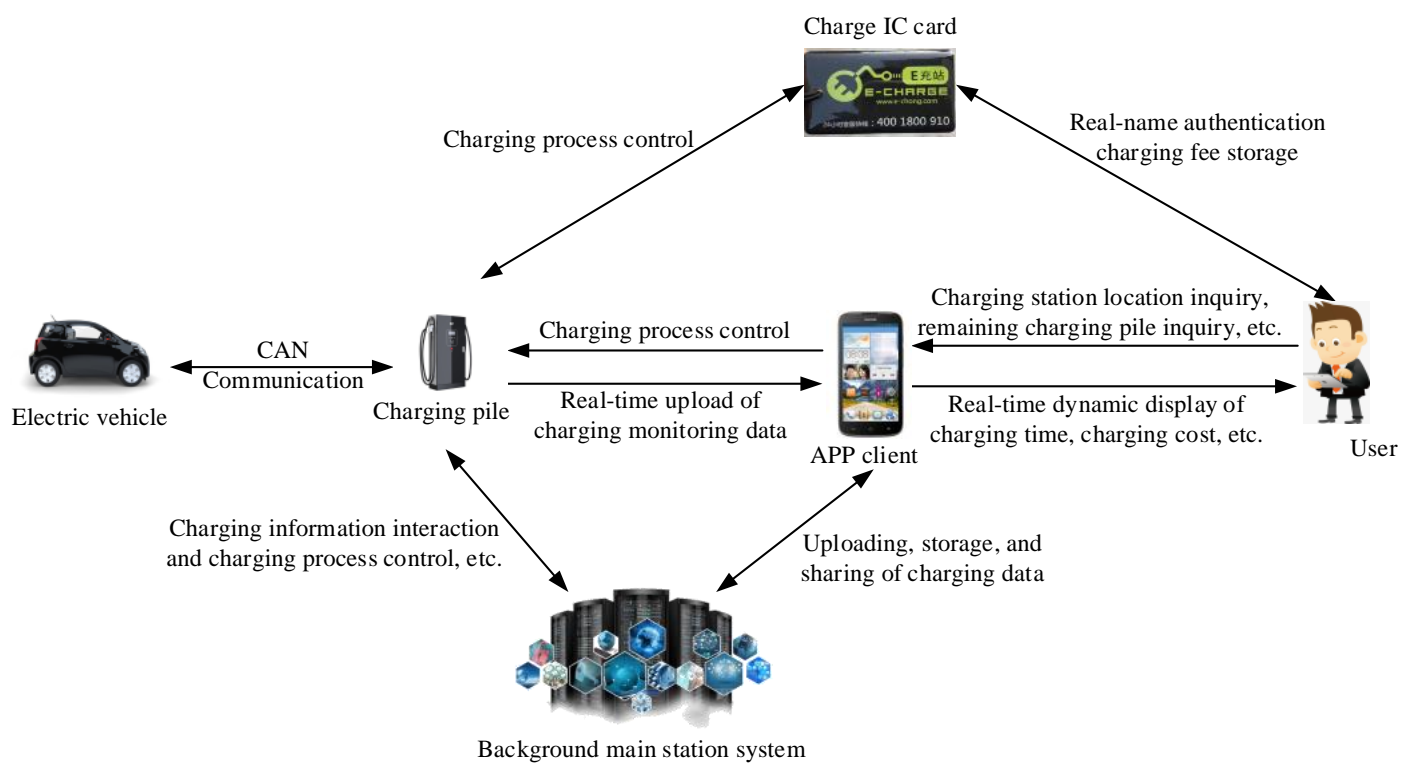

Figure 4. Communication structure diagram of charging pile.

\subsection{Charging Safety Evaluation Index System and Early Warning Model}

The prerequisite to effectively evaluate the charging safety state of electric vehicles is to build a charging safety evaluation index system, which should be built through scientific and standard methods to realize the accurate evaluation of the charging state. Before building the system, the evaluator with theoretical knowledge should learn more about the evaluation object and evaluation target. Figure 5 presents the flow chart of the construction of a charging safety evaluation index system.

The building of a charging safety evaluation index system should not only consider the safety evaluation indicators of battery but also the safety evaluation indicators of charging equipment and an even distribution grid. In addition, considering the complexity of charging safety evaluation, it is necessary to screen the system based on the hierarchical, scientific, and comprehensive principles, refine it layer by layer, and finally establish a comprehensive charging safety evaluation index system. The determination of weight is a key question. Whether the weight of indicators can be effectively determined is related to the accuracy of the evaluation method. Reference [50] designs a comprehensive charging safety evaluation index system from three aspects of power battery, charging equipment and distribution grid, and uses the gray correlation method to determine the weight of indicators. Reference [128] proposes a new approach based on comprehensive weights to solve the problem of electrical safety protection for electric vehicle charging equipment. The method quantifies the abstraction capability of electrical safety and tests a charging device to verify its effectiveness. 


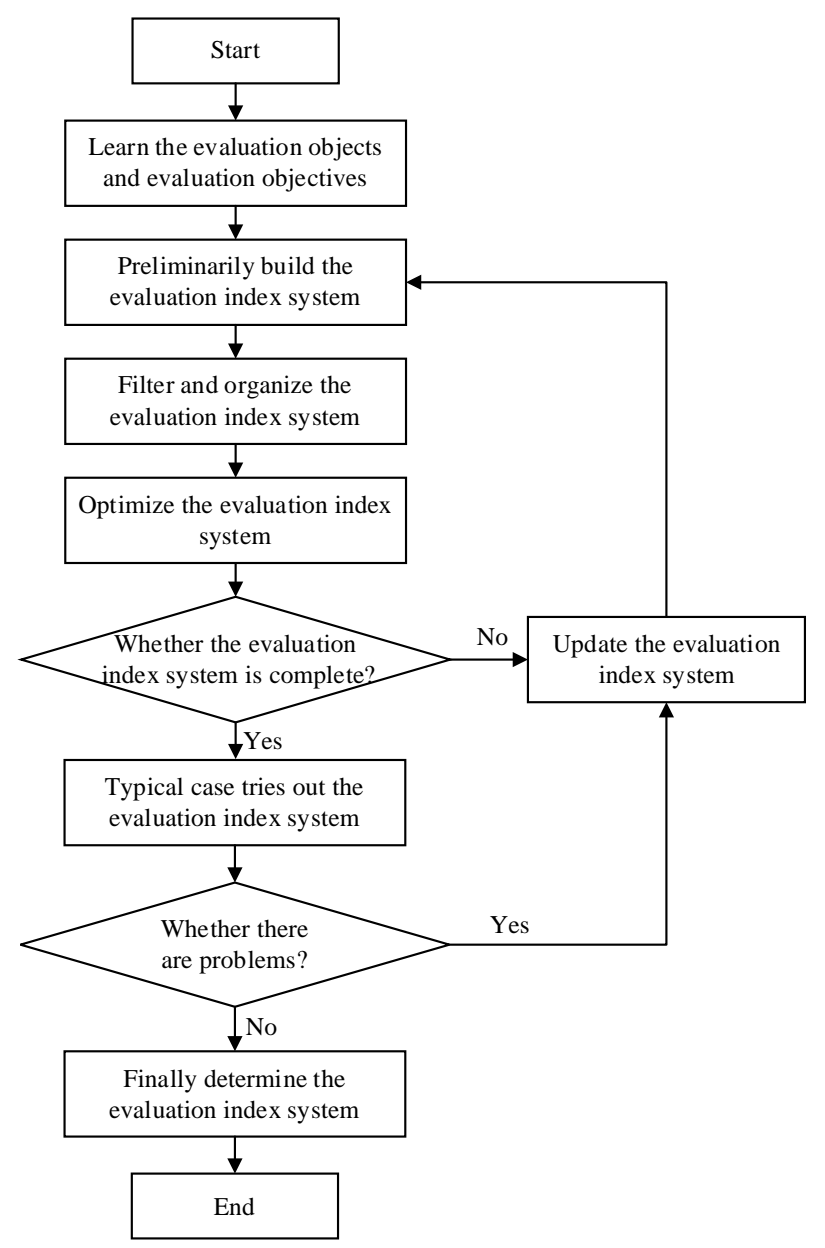

Figure 5. Flow chart of the building of a charging safety evaluation index system.

The construction of the early warning model is related to the results of charging safety evaluation, which helps to improve the charging safety protection capacity of electric vehicles [50]. Key parameters such as battery charge state, maximum voltage and maximum current are the initial input of the general early warning model, and their timeliness and integrity have a great impact on the accuracy of early warning results. Therefore, the design of the electric vehicle charging safety protection monitoring device is one of the effective means to improve the accuracy of early warning results. Reference [114] designs a charging safety protection monitoring device of electric vehicles, and then establishes an early warning model based on the charging equipment operation state by the fuzzy comprehensive evaluation method. Combined with the national standards for charging safety protection, Reference [117] analyzes the factors affecting the charging safety of electric vehicles and builds a new charging safety protection warning model by learning an optimized neural network training mechanism and identification characteristics and selects specific cases to verify the effectiveness and accuracy of the model.

\section{Research Prospect}

Currently, China is vigorously developing the electric vehicle-related industries, spurring the charging pile technology towards high-power, intelligence, and wireless charging. However, the research on the integrated safety protection of electric vehicles is immature, and some standards and safety protection measures are imperfect. Thus, ensuring the charging safety of electric vehicles is still the primary task. The authors believe that further research from the following aspects will help to improve the safety of the charging system. 


\subsection{Improve the Standard System of Charging Safety of Electric Vehicles}

China has made great progress in the research and development and industrialization promotion of electric vehicle-related technologies, but the task of making and revising standards of electric vehicles is still arduous. It is necessary to improve relevant standards as soon as possible to make up for the shortage of existing standards. For example, there is no complete standard system for the charging safety information of electric vehicles. However, with the development of emerging technologies, such as intelligent networks, electric vehicles will gradually become energy information carriers and logistics terminals. A large number of information interactions will inevitably pose information security risks, which will have a growing impact on the charging safety of electric vehicles. Some enterprises and governments have put forward the safety standards and norms for the information interaction safety of charging equipment, which, however, need to be further studied to improve the standard system for charging safety of electric vehicles.

\subsection{Build a More Complete Charging Safety Database}

The analysis of the influencing factors of charging safety is the theoretical basis for studying the charging safety of electric vehicles. With the increasingly complex charging environment of electric vehicles, the influencing factors of charging safety show a diversified and multi-dimensional expansion trend. Impact factors often interact and occur simultaneously, which may pose a safety threat to personnel, vehicles, and surrounding facilities. Based on the current development status of a charging safety system, it is necessary to make full use of the exchange data of massive charging system, extract and integrate the information affecting the charging safety of electric vehicles and charging piles through physical extraction, relationship extraction and attribute extraction, establishing a more complete charging safety database. For example, charging current is one of the important parameters to characterize the charging safety of electric vehicles. The relationship between safety current and battery state of charge is affected by many complex factors, which is difficult to reveal through modeling and can only be solved by establishing a database in a data-driven way. Through analyzing the action mechanism and coupling characteristics between the influencing factors, we can forecast and prevent the potential risks during charging, so as to protect people and equipment.

\subsection{Establish a High-Credibility Battery Fault Diagnosis Model}

The battery has complex characteristics in the battery fault state, and modeling it is an effective way for fault diagnosis and characteristic analysis. Most current battery safety studies rely on electrochemical models or equivalent circuit models, but the feasibility and accuracy of these diagnostic models in the battery fault state need to be studied. Many scholars use the " $0 / 1$ " diagnosis method of a single fault to diagnose the battery fault. However, in the actual scene, the battery fault category of the electric vehicle is unknown and uncertain, and even many types of faults occur simultaneously, and the influence characteristics are coupled to each other. For example, the cause of the high temperature of the battery may be the short circuit of the battery, or the MIS operation of the BMS, and the BMS may also cause the short circuit. The credibility of the existing battery fault diagnosis methods is difficult to guarantee. Therefore, the previous battery fault diagnosis model cannot accurately describe the fault action mechanism. Establishing a battery fault diagnosis model with high credibility helps to reveal the nature of the battery charging fault and improve the safety protection level of battery charging. A high-credibility battery fault diagnosis model can more accurately reveal the influence mechanism between charging safety and influencing factors, so as to restore the possible causes of faults and timely identify and remove the hidden dangers of faults in combination with the evaluation criteria. 


\subsection{Establish a Sounder Dynamic Monitoring and Fault Early Warning Mechanism for Charging Equipment}

During charging, the fluctuation of parameters of charging equipment, such as internal temperature, charging pile input/output voltage, and battery charge state, have a great impact on the safety protection of charging equipment. Once the monitoring system misreports or misses the above safety risks or fails to timely give an early warning, it may cause safety accidents. It is urgent to strengthen the dynamic monitoring of charging equipment, such as the monitoring of the charging equipment insulation state and the monitoring of the electric vehicle battery charging state. Furthermore, improving the dynamic monitoring mechanism and fault warning mechanism is an important measure to improve the safety protection ability of the electric vehicle charging system, which can not only dynamically monitor the key parameters of electric vehicles during charging but also give early warning of potential failure risks to effectively ensure the safety of electric vehicles and charging equipment.

\subsection{Strengthen the Research on Charging Safety Protection Technology of Electricity Quality Fluctuation}

A power grid is the direct source of energy supply of the charging station, and the reliability of its electricity quality has a great impact on the stable operation of a charging pile. Scholars now have only explored the influence mechanism between the change of electricity quality and charging safety. For example, they found that the frequent voltage fluctuations of the distribution grid are directly connected to the charging station, and intense surge impact and high harmonic content may lead to abnormal heating and low operation efficiency of the rectifier module inside the charging pile, and even the operation failure of the charging pile. However, there is little theoretical and technical research about the safety protection for electricity quality fluctuations, leaving a research gap. Therefore, it is urgent to use the smart grid, 5G technology, big data technology and other emerging technologies to develop the real-time charging safety monitoring and protection device for electricity quality fluctuations of charging stations and develop the corresponding software and hardware system to improve and upgrade the charging safety protection system. For example, 5G technology has faster data transmission speed and larger data bandwidth, and the intelligent control platform can realize accurate data calculation and online optimization of instructions. The above two technologies can help the system realize accurate analysis and dynamic online monitoring of power quality.

\subsection{Optimize the Charging Data Storage Scheme Based on Emerging Technologies Such as Blockchain}

The electric vehicle charging platform, an important component of future smart grids, will store a large number of user charging transaction data, personal privacy data and other related data. In the existing charging pile sharing platform, the user charging transaction data, personal privacy data and other related data are stored in a centralized database. However, this excessively centralized storage strategy is very vulnerable to malicious network attacks, which causes security problems such as single-point failure and even malicious tampering of important transaction data, thus causing leakage of a large number of user privacy data. To solve the above problems, blockchain is an effective solution. Blockchain is essentially a decentralized database. It is a new application mode of computer technology such as distributed data storage, point-to-point transmission, consensus mechanism and encryption algorithm. It does not need to rely on centralized institutions but can directly complete the real-time transmission of values through smart contracts and tokens on the blockchain. The blockchain can be used to select several charging stations in the electric vehicle charging platform as data center nodes and ensure that the user can encrypt and control the right to use the personal data after the transaction. Each data center node uses a consensus mechanism for synchronous and decentralized storage of the encrypted data, so as to optimize the charging data storage scheme. 


\section{Conclusions}

To solve the charging safety problems, this paper explored the influencing factors of charging safety and charging safety protection of electric vehicles, analyzed the correlation between the influencing factors of charging safety and the implied charging faults, summarized the research achievements of charging safety by scholars from different countries, providing ideas and solutions to problems for researchers engaged in the electric vehicle industry, and proposed the focus of future charging safety research, which has reference value and reference significance for the charging safety research of electric vehicles: (1) The standard system related to electric vehicle charging safety is not perfect, and further research is needed. (2) With the development of information and intelligent technology, we will obtain a significant amount of data related to electric vehicles in the future. It is necessary to establish an advanced charging safety database. (3) The fault characteristics of electric vehicles are relatively complex, so it is necessary to build a more accurate and reliable charging fault diagnosis model. (4) Due to the high randomness of the electric vehicle load, it is necessary to carry out dynamic monitoring and early fault warnings for charging facilities. (5) The diversity of the power load and the access to new energy will further increase the fluctuation of power quality. Therefore, it is needed to study the charging safety protection technology for power quality fluctuations.

Author Contributions: Conceptualization, L.J. and T.L.; methodology, L.J. and X.D.; software, Y.Z.; validation, J.Z. All authors have read and agreed to the published version of the manuscript.

Funding: This work was funded by the State Grid Technology Project "Research on Interaction between Large-scale Electric Vehicles and Power Grid and Charging Safety Protection Technology" (5418-202071490A-0-0-00) from State Grid Corporation of China.

Conflicts of Interest: The authors declare no conflict of interest.

\section{Appendix A}

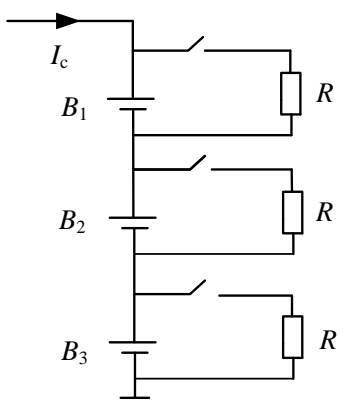

Figure A1. Circuit diagram of dissipative shunt equalization method.

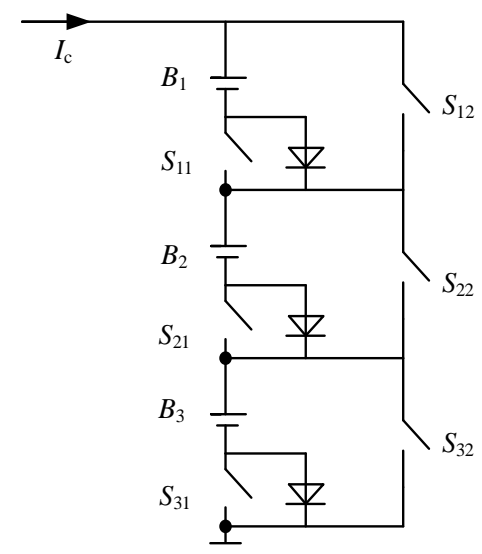

Figure A2. Circuit diagram of complete shunt equalization method. 


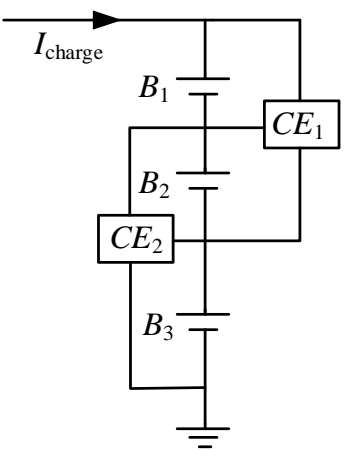

Figure A3. Circuit diagram of isomorphic CE equalization method.

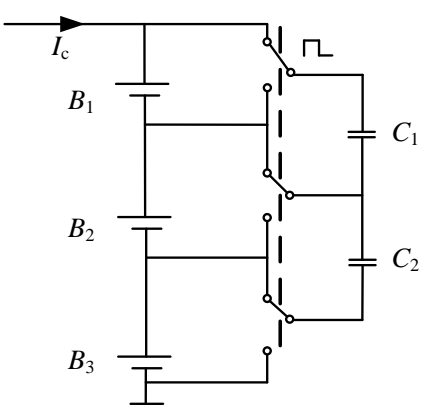

Figure A4. Circuit diagram of multi-switching capacitance method.

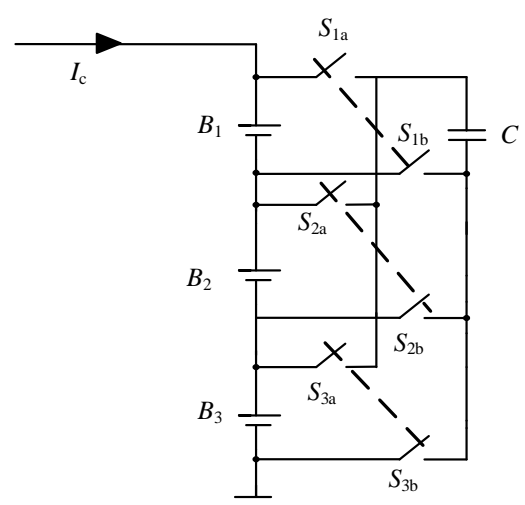

Figure A5. Circuit diagram of single switching capacitance method.

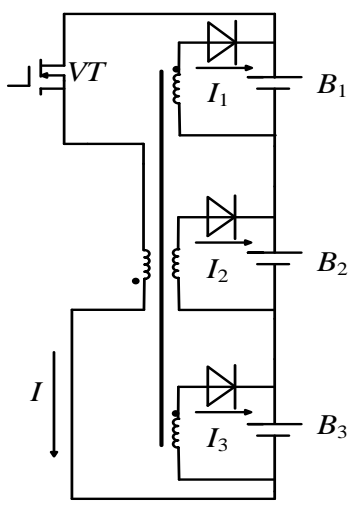

Figure A6. Circuit diagram of multi-winding transformer method. 


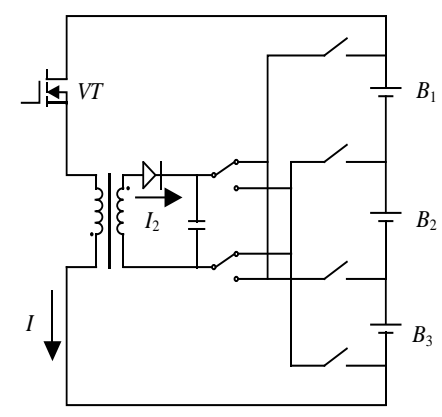

Figure A7. Circuit diagram of switching transformer method.

\section{References}

1. Qiang, X.; Zhong, C.; Zhaoying, L.; Yu, L.; Yi, L. Route planning and charging navigation strategy for electric vehicles based on real-time traffic information. Proc. CSEE 2020, 40, 534-550. [CrossRef]

2. Hong, L.; Jun, Y.; Shaoyun, G.; Jun, H. Dynamic response of electric vehicle and fast charging stations considering multi vehicle interaction. Proc. CSEE 2020, 40, 6455-6468.

3. Gangui, Y.; Huanan, L.; Ninghui, H.; Songsong, C.; Dongmin, Y. An optimization method for location and capacity determination of charging stations considering spatial and temporal distribution of electric vehicles. Proc. CSEE 2021, 41, 6271-6284.

4. Nan, L. Review on electric vehicle safety issues considering international regulations. Environ. Technol. 2020, 38, $216-223$.

5. Hanxiao, M. Research on safety test of electric vehicle. Sci. Technol. Innov. 2019, 29, 69-70.

6. Angel, R.M.; Thomas, N. Injury surveillance and safety considerations for large- format lead-acid batteries used in mining applications. IEEE Trans. Ind. Appl. 2016, 52, 1925-1930.

7. Hongxia, G.; Yuechun, Q.; Hongying, Z. The influence of over discharge on the performance of sintered Ni/MH battery. Batteries 2009, 39, 159-160.

8. Spotnitz, R.; Franklin, J. Abuse behavior of high-power, lithium-ion cells. J. Power Sources 2003, 113, 81-100. [CrossRef]

9. Manthiram, A. Materials Challenges and Opportunities of Lithium Ion Batteries. J. Phys. Chem. Lett. 2011, 2, 176-184. [CrossRef]

10. Xuning, F. Mechanism, Modeling and Prevention of Thermal Runaway Induction and Expansion of Vehicle Li Ion Power Battery; Tsinghua University: Beijing, China, 2016.

11. Ruguang, F.; Xuan, X.; Nan, J.; Hongting, W.; Jingxin, S. Design of charging safety protection system for electric bus. Mod. Manuf. Technol. Equip. 2019, 4, 104-105.

12. Xiong, W. Functional Safety Analysis and Fault Diagnosis of Power Battery Charging; Xihua University: Chengdu, China, 2020.

13. Zhijing, H.; Mao, L. Electric Vehicle Charging Safety Analysis and Solution Research; Shandong Industrial Technology: Jinan, China, 2017; p. 47.

14. Yilmaz, M.; Krein, P.T. Review of battery charger topologies, charging power levels, and infrastructure for plug-in electric and hybrid vehicles. Power Electron. IEEE 2012, 92, 50-59. [CrossRef]

15. Fleischhammer, M.; Waldmann, T.; Bisle, G.; Hogg, B.-I.; Wohlfahrt-Mehrens, M. Interaction of cyclic ageing at high-rate and low temperatures and safety in lithium-ion batteries. J. Power Sources 2015, 274, 432-439. [CrossRef]

16. Binghe, L.; Fucheng, Z.; Chuanyun, J. Trouble analysis and clearing of high voltage insulation fault during charging for plug-in hybrid bus. Bus Technol. Res. 2015, 37, 44-46, 61.

17. Nian, L.; Bin, D. Discussion on security message of IEC 60870-5-104 telecontrol protocol. Autom. Electr. Power Syst. 2005, 29, 93-96.

18. Fries, S.; Falk, R. Electric vehicle charging infrastructure-security considerations and approaches. In Proceedings of the Fourth International Conference on Evolving Internet-INTERNET 2012, Venice, Italy, 24-29 June 2012; pp. 58-64.

19. FDIS 27001-2005, BS 7799-2-2005(ISO/IEC FDIS 27001-2005) Draft: Information Technology. Security Technology. Information Safety Management System. Requirements (See Item Summary for Details of Specific Offer); ISO/IEC: Geneva, Switzerland, 2005.

20. GB/T 20984-2007, Information Safety Technology Information Safety Risk Assessment Specification; Standardization Administration Committee of China: Beijing, China, 2007.

21. GB/Z 24364-2009, Information Safety Technology Information Safety Risk Management Guide; Standardization Administration Committee of China: Beijing, China, 2009.

22. GB/T 31509-2015, Information Safety Technology Information Safety Risk Assessment Implementation Guide; Standardization Administration Committee of China: Beijing, China, 2015.

23. GB/T 31722-2015, Information Technology Security Technology Information Safety Risk Management; Standardization Administration Committee of China: Beijing, China, 2015.

24. Pannala, S.; Turner, J.A.; Allu, S.; Elwasif, W.R.; Kalnaus, S.; Simunovic, S.; Kumar, A.; Billings, J.J.; Wang, H.; Nanda, J. Multiscale modeling and characterization for performance and safety of lithium-ion batteries. J. Appl. Phys. 2015, 118, 072017. [CrossRef]

25. Xia, B.; Shang, Y.; Nguyen, T.; Mi, C. A correlation based fault detection method for short circuits in battery packs. J. Power Sources 2017, 337, 1-10. [CrossRef] 
26. Jing, Z.; Wei, S.; Yuanxing, Z.; Jing, Z.; Taoyong, L. Analysis of safety factors and dynamic warning during charging process of electric vehicle. Power Technol. 2019, 43, 861-863+868.

27. Xia, B.; Mi, C.; Chen, Z.; Robert, B. Multiple cell lithium-ion battery system electric fault online diagnostics. In Proceedings of the 2015 IEEE Transportation Electrification Conference and Expo (ITEC), Dearborn, MI, USA, 14-17 June 2015; pp. 1-7. [CrossRef]

28. Yao, X. Design of Lithium-Ion Battery Fault Analysis and Processing System; University of Electronic Science and Technology of China: Chengdu, China, 2018.

29. Longyun, S. Protection of Electric Vehicle Charging Pile Against Electric Shock. Commun. Power Supply Technol. 2020, 37, 218-219.

30. Broek FV, D.; Poll, E.; Vieira, B. Securing the information infrastructure for EV charging. In Wireless and Satellite System; Springer International Publishing: Berlin, Germany, 2015; pp. 61-74.

31. Weixian, W.; Jie, Z.; Heping, T.; Zhen, C.; Xiaoxi, Y. Design and implementation of information safety protection scheme of electric vehicle charging pile-background service management center. Power Constr. 2019, 40, 55-62.

32. Lu, L.; Han, X.; Li, J.; Hua, J.; Ouyang, M. A review on the key issues for lithium-ion battery management in electric vehicles. J. Power Sources 2013, 226, 272-288. [CrossRef]

33. Wu, C.; Zhu, C.; Ge, Y.; Zhao, Y. A Review on Fault Mechanism and Diagnosis Approach for Li-Ion Batteries. J. Nanomater. 2015, 2015, 1-9. [CrossRef]

34. Wang, S.; Jin, S.; Bai, D.; Fan, Y.; Shi, H.; Fernandez, C. A critical review of improved deep learning methods for the remaining useful life prediction of lithium-ion batteries. Energy Rep. 2021, 7, 5562-5574. [CrossRef]

35. Wang, Z.; Feng, G.; Zhen, D.; Gu, F.; Ball, A. A review on online state of charge and state of health estimation for lithium-ion batteries in electric vehicles. Energy Rep. 2021, 7, 5141-5161. [CrossRef]

36. Omariba, Z.B.; Zhang, L.; Sun, D. Review of Battery Cell Balancing Methodologies for Optimizing Battery Pack Performance in Electric Vehicles. IEEE Access 2019, 7, 129335-129352. [CrossRef]

37. Kexin, W.; Qiaoyan, C. State estimation of li-ion power batteries based on adaptive unscented kalman filters. Proc. CSEE 2014, 34, $445-452$.

38. Gangui, Y.; Hongbo, L.; Shuangming, D.; Changxing, C.; Ying, L.; Junhui, L.; Bo, X. Energy storage battery state estimation based on model parameter identification. Proc. CSEE 2020, 40, 8145-8154, 8251.

39. Ge, Z.; Xin, Z.; Guodong, L.; Zhidan, X.; Yuexin, Y. Research on vehicular lithium-ion battery system with charging and replacing technology. Power Technol. 2017, 41, 641-643.

40. Alvarez, B.L.; Garcia, S.V.; Ramis, C.F. Developing an active balancing model and its Battery Management System platform for lithium-ion batteries. In Proceedings of the 2013 IEEE International Symposium on Industrial Electronics, Taipei, Taiwan, 28-31 May 2013.

41. Janakeeraman, S.V.; Singh, J.; Kuitche, J.; Mallineni, J.K.; TamizhMani, G. A statistical analysis on the cell parameters responsible for power degradation of fielded PV modules in a hot-dry climate. In Proceedings of the 2014 IEEE 40th Photovoltaic Specialist Conference (PVSC), Denver, CO, USA, 8-13 June 2014; pp. 3234-3238.

42. Jiawang, Z.; Rong, Z.; Yongyang, Z.; Chun, L.; Guilin, L. Research on safety of lithium-ion battery for electric vehicle. Power Technol. 2018, 42, 1134-1135, 1179.

43. Jiyong, C.; Xinxin, L. Analysis and Exploration on safety problems of lithium-ion batteries for new energy vehicles. Times Agric. Mach. 2019, 46, 63-64.

44. Mengdi, Z. Research on Thermal Safety Response and Overheating Critical Behavior Characteristics of Agricultural Machinery Power Battery in the New Era; Jilin University: Jilin, China, 2019.

45. Maleki, H.; Howard, J.N. Internal short circuit in Li-ion cells. J. Power Sources 2009, 191, 568-574. [CrossRef]

46. Wei, W.; Youren, W. Review of internal short circuit of lithium-ion battery. Mach. Manuf. Autom. 2020, 49, 169-172.

47. Zeyu, C.; Rui, X.; Fengchun, S. Research Status and Analysis for Battery Safety Accidents in Electric Vehicles. Chin. J. Mech. Eng. 2019, 55, 93-104, 116. [CrossRef]

48. Qingsong, Z.; Ziheng, Z.; Wei, B. Thermal safety analysis of ternary lithium-ion battery under overcharge condition. Fire Sci. Technol. 2020, 39, 713-717.

49. Yongxing, G. Research on Key Technology Foundation and Safety of Lithium-Ion Power Battery Manufacturing; Central South University: Changsha, China, 2010.

50. Ouyang, D.; He, Y.; Chen, M.; Liu, J.; Wang, J. Experimental study on the thermal behaviors of lithium-ion batteries under discharge and overcharge conditions. J. Therm. Anal. Calorim. 2017, 132, 65-75. [CrossRef]

51. Wei, S. Research on Integrated Safety Warning and Protection System of Electric Vehicle Charging; Nanjing University of Posts and Telecommunications: Nanjing, China, 2018.

52. Yan, W. Study on Electrolyte Solution for Lithium-Ion Battery with Wide Temperature Range; Tianjin University: Tianjin, China, 2007.

53. Minyi, C.; Ei, Z.; Jing, L.; Kangli, W.; Kai, J.; Min, Z. Review on Balancing Topology of Lithium-ion Battery Pack. Proc. CSEE 2021, 41, 5294-5311.

54. Yang, L.; Caiping, Z.; Jiuchun, J.; Weige, Z.; Linjing, Z. Research on capacity difference identification method of lithium-ion battery pack. Proc. CSEE 2021, 41, 1422-1430.

55. Yunlong, G.; Ziqiang, C. Inconsistency identification and state estimation of series-connected lithium-ion batteries pack based on STF\&LM algorithm. Proc. CSEE 2018, 38, 4271-4280+4333. 
56. Shuai, W.; Zhongdong, Y.; Zhong, Z.; Yuanzhao, H.; Yinshun, W.; Yuting, Y. The influence of cell parameters inconsistency on the performance of different topological battery modules. Electr. Meas. Instrum. 2020, 57, 76-82.

57. Wang; Tianfu; Qiang, L.; Zhiqiang, L. Design and implementation of charging and discharging intelligent management system for power lithium battery pack. Power Technol. 2011, 35, 1069-1071.

58. Ming, G. Experimental Study on Thermal Management of Li Ion Battery Pack for Pure Electric Vehicle; Tianjin University: Tianjin, China, 2016.

59. Mingyu, Z.; Gang, W.; Yinghui, W.; Guangming, S. Design and implementation of a supervisory and control system for charging facilities of electric vehicles. Autom. Electr. Power Syst. 2011, 35, 65-69+98.

60. Shengguo, G.; Yunxiang, L.; Dongxue, X.; Xiangnan, F. Research on safety protection of charging system of electric vehicle. Ind. Eng. Des. 2020, 2, 121-122.

61. Ping, Z.; Lin, S.; Yuejiu, Z.; Yangminggao, O.; Long, Z. Experimental study on characteristics of over-discharged Li-NCM battery. J. Automob. Saf. Energy Sav. 2017, 8, 72-78.

62. Peng, Y. Research on off Board DC Charging Communication and Safety System; North China Electric Power University (Beijing): Beijing, China, 2017.

63. GB/T 27930-2015, Communication Protocol between Electric Vehicle Off Board Conductive Charger and Battery Management System; Standardization Administration Committee of China: Beijing, China, 2015.

64. GB/T 18487.1-2015, Conductive Charging System for Electric Vehicles Part 1: General Requirements; Standardization Administration Committee of China: Beijing, China, 2015.

65. Chun, H.; Zhuo, C.; Jintao, F.; Qingwei, Y.; Xiang, L. Analysis and solutions on the safety of electric vehicle charging. Power Supply Consum. 2017, 34, 12-18, 50.

66. Guoxin, H. Safety Design and Experimental Study of PHEV Power Battery System; South China University of Technology: Guangzhou, China, 2016.

67. Xiang, T.; Yingfeng, C.; Xiao, X.; Bin, H.; Anping, M. Analysis on influencing factors of conductive charging safety for electric vehicles. China Automob. 2019, 12, 45-49.

68. Peimin, H. Electric vehicle charging safety analysis and Solutions. Time Car 2018, 9, 71-72.

69. Lei, Y. Research and Implementation of information safety Protection Technology for Distributed Electric Vehicle Charging Post. Manag. Technol. SME (Next Ten Days) 2020, 2, 165-166.

70. Baojun, Z. Research and Implementation of Information Safety Protection Technology for Distributed Electric Vehicle Charging Pile; Harbin Institute of Technology: Harbin, China, 2018.

71. Jun, L.; Ling, X. Aging Testing System for Rectifier Module of Electric Vehicle Charger Based on $\mu$ C/OS-II Embedded System. Digit. Commun. World 2017, 7, 3-240.

72. NB/T 33001-2010, Technical Specification for Off Board Conductive Charger of Electric Vehicle; China National Energy Administration: Beijing, China, 2010.

73. Daoping, W.; Yaoxi, W.; Yu, T.; Xinhui, L. How to do the lightning protection work of charging station well. China Meteorological Society. In Proceedings of the 2018 16th Lightning Protection and Disaster Reduction Forum, Hefei, China, 24 October 2018; China Meteorological Society: Beijing, China, 2018; p. 3.

74. Zuoqin, Z. Construction of qualified charging pile and safety firewall. Fujian Qual. Technol. Superv. 2018, 12, 35-36.

75. Zuoqin, Z. Discussion on performance and safety problems of electric vehicle DC charging spot. Qual. Technol. Superv. Res. 2020, 1,39-42.

76. Hong, C. Analysis and research on charging safety of electric vehicles. Intern. Combust. Engine Parts 2017, 21, 113-114.

77. Quan, W.; Miaomiao, S.; Tiange, D. On the safety of lithium-ion batteries for new energy vehicles. Mach. Manuf. 2019, 57, 55-56+93.

78. Fei, G.; Yanli, Z.; Chuang, Q.; Songcen, W.; Kai, Y. Excitation source analysis of lithium-ion batteries safety accidents. Power Technol. 2019, 43, 453-457.

79. Ouyang, M.; Zhang, M.; Feng, X.; Lu, L.; Li, J.; He, X.; Zheng, Y. Internal short circuit detection for battery pack using equivalent parameter and consistency method. J. Power Sources 2015, 294, 272-283. [CrossRef]

80. Feng, X.; Pan, Y.; He, X.; Wang, L.; Ouyang, M. Detecting the internal short circuit in large-format lithium-ion battery using model-based fault-diagnosis algorithm. J. Energy Storage 2018, 18, 26-39. [CrossRef]

81. Feng, X.; Weng, C.; Ouyang, M.; Sun, J. Online internal short circuit detection for a large format lithium ion battery. Appl. Energy 2016, 161, 168-180. [CrossRef]

82. Kong, X.; Zheng, Y.; Ouyang, M.; Lu, L.; Li, J.; Zhang, Z. Fault diagnosis and quantitative analysis of micro-short circuits for lithium-ion batteries in battery packs. J. Power Sources 2018, 395, 358-368. [CrossRef]

83. Zhang, M.; Liu, L.; Stefanopoulou, A.; Siegel, J.; Lu, L.; He, X.; Ouyang, M. Fusing Phenomenon of Lithium-Ion Battery Internal Short Circuit. J. Electrochem. Soc. 2017, 164, A2738-A2745. [CrossRef]

84. Seo, M.; Goh, T.; Park, M.; Koo, G.; Kim, S.W. Detection of Internal Short Circuit in Lithium Ion Battery Using Model-Based Switching Model Method. Energies 2017, 10, 76. [CrossRef]

85. Fernandes, Y.; Bry, A.; de Persis, S. Identification and quantification of gases emitted during abuse tests by overcharge of a commercial Li-ion battery. J. Power Sources 2018, 389, 106-119. [CrossRef] 
86. Fernandes, Y.; Bry, A.; de Persis, S. Thermal degradation analyses of carbonate solvents used in Li-ion batteries. J. Power Sources 2019, 414, 250-261. [CrossRef]

87. Chuang, Q.; Yanli, Z.; Fei, G.; Songcen, W.; Kai, Y.; Jianxin, N.; Qingjie, J. Thermal runaway analysis of lithium-ion battery with overcharge. J. Beijing Univ. Technol. 2017, 37, 1048-1055.

88. Lin, C.T.; Cui, C.; Xu, X.T. Lithium-ion battery electro-thermal model and its application in the numerical simulation of short circuit experiment. In Proceedings of the 2013 World Electric Vehicle Symposium and Exhibition (EVS27), Barcelona, Spain, 17-22 November 2013; pp. 1-8.

89. Huang, P.; Verma, A.; Robles, D.J.; Wang, Q.; Mukherjee, P.; Sun, J. Probing the cooling effectiveness of phase change materials on lithium-ion battery thermal response under overcharge condition. Appl. Therm. Eng. 2018, 132, 521-530. [CrossRef]

90. Ye, J.; Chen, H.; Wang, Q.; Huang, P.; Sun, J.; Lo, S.M. Thermal behavior and failure mechanism of lithium ion cells during overcharge under adiabatic conditions. Appl. Energy 2016, 182, 464-474. [CrossRef]

91. Yong, Z. Research on Overcharge and over-Discharge Fault Diagnosis of Lithium-Ion Battery; Chang'an University: Xi'an, China, 2016.

92. Yanxian, S.; Zhaohua, J. Safety of overcharge test of lithiumion batteries. Power Technol. 2019, 43, 884-886.

93. Xiugang, L. Research on Active Equalization Strategy in Charging Process of Power Battery Pack; Jilin University: Jilin, China, 2017.

94. Minji, Z.; Yangzhou, S.; Jia, L.; Yujie, Z.; Zhibin, L. The balancing efficiency analysis of the switched-capacity method. Energy Storage Sci. Technol. 2016, 5, 222-227.

95. Shibata, H.; Taniguchi, S.; Yamasaki, K. Management of serially-connected battery system using multiple switches. In Proceedings of the 4th IEEE International Conference on Power Electronics and Drive Systems, Denpasar, Indonesia, 25 October 2001; Volume 2, pp. 508-511.

96. Nishijima, K.; Sakamoto, H.; Harada, K. A PWM controlled simple and high performance battery balancing system. In Proceedings of the 2000 IEEE 31st Annual Power Electronics Specialists Conference, Conference Proceedings (Cat. No.00CH37018), Galway, Ireland, 23-23 June 2000; Volume 1, pp. 517-520. [CrossRef]

97. Kimball, J.W.; Krein, P.T. Analysis and design of switched capacitor converters. In Proceedings of the Twentieth Annual IEEE Applied Power Electronics Conference and Exposition-APEC 2005, Austin, TX, USA, 6-10 March 2005; Volume 3, pp. $1473-1477$.

98. Cao, J.; Schofield, N.; Emadi, A. Battery balancing methods: A comprehensive review. In Proceedings of the 2008 IEEE Vehicle Power and Propulsion Conference, Harbin, China, 3-5 September 2008; pp. 1-6. [CrossRef]

99. Kai, Z.; Li, S.; Shaogui, F. Research on design methodology of super capacitor balancing system based on multi-winding transformer. Power Electron. 2018, 52, 37-40.

100. Cho, W.; Kim, S.-M.; Lee, K.-W.; Song, J.H.; Jo, Y.N.; Yim, T.; Kim, H.; Kim, J.-S.; Kim, Y.-J. Investigation of new manganese orthophosphate $\mathrm{Mn}_{3}\left(\mathrm{PO}_{4}\right)_{2}$ coating for nickel-rich $\mathrm{LiNi}_{0.6} \mathrm{Co}_{0.2} \mathrm{Mn}_{0.2} \mathrm{O}_{2}$ cathode and improvement of its thermal properties. Electrochim. Acta 2016, 198, 77-83. [CrossRef]

101. Baginska, M.; Blaiszik, B.J.; Merriman, R.J.; Sottos, N.R.; Moore, J.S.; White, S.R. Automatic shutdown of lithium-ion batteries using thermoresponsive microspheres. Adv. Energy Mater. 2012, 2, 583-590. [CrossRef]

102. Dianmo, Z.; Xin, C.; Hongxiang, G.; Weiwei, L. Preparation and electrochemical properties of silicon / carbon anode materials for lithium-ion batteries. Mod. Chem. Ind. 2018, 38, 118-121+123.

103. Ko, Y.; Yoo, H.; Kim, J. Curable polymeric binder-ceramic composite-coated superior heat-resistant polyethylene separator for lithium ion batteries. RSC Adv. 2014, 4, 19229-19233. [CrossRef]

104. Yuhong, C.; Liang, W.; He, Z.; Yawei, H. Study on TDCPP as flame retardant additive for lithium-ion battery. Mod. Chem. Ind. 2018, 38, 128-130.

105. Zeng, Z.; Wu, B.; Xiao, L.; Jiang, X.; Chen, Y.; Ai, X.; Yang, H.; Cao, Y. Safer lithium ion batteries based on nonflammable electrolyte. J. Power Sources 2015, 279, 6-12. [CrossRef]

106. Zeng, Z.; Murugesan, V.; Han, K.S.; Jiang, X.; Cao, Y.; Xiao, L.; Ai, X.; Yang, H.; Zhang, J.-G.; Sushko, M.L.; et al. Non-flammable electrolytes with high salt-to-solvent ratios for Li-ion and Li-metal batteries. Nat. Energy 2018, 3, 674-681. [CrossRef]

107. Ziqi, Z.; Xiaoyu, J.; Ran, L.; Dingding, Y.; Xinping, A.; Hanxi, Y.; Yuliang, C. A safer sodium-ion battery based on nonflammable organic phosphate electrolyte. Adv. Sci. 2016, 3, 1600066.

108. Xiaodong, H.; Shunli, L.; Yulin, L. Application advances of modified diaphragm and interlayer in lithium-sulfur batteries. Mod. Chem. Ind. 2018, 38, 30-33, 35.

109. Pekala, R.; Patil, Y.; Peddini, S. Development of Separators with Inorganic Fillers for Advanced Lithium-Ion Batteries; Knowledge Foundation: New York, NY, USA, 2010; p. 155.

110. Li, L.; Bo, P.; Fei, L.; Qiwei, H.; Beihu, L. Research Progress of all-solid-state lithium-ion battery. Mar. Power Technol. 2018, 38, 45-47.

111. Hong, L. All solid-state lithium battery: Dream into reality. Energy Storage Sci. Technol. 2018, 7, $188-193$.

112. Xiong, J.; Banvait, H.; Li, L.; Chen, Y.; Xie, J.; Liu, Y.; Wu, M.; Chen, J. Failure detection for over-discharged Li-ion batteries. In Proceedings of the 2012 IEEE International Electric Vehicle Conference, Greenville, SC, USA, 4-8 March 2012; pp. 1-5. [CrossRef]

113. Zhao, M.; Wu, J.; Zhang, W.; Gu, X.; Wu, Y. Optimal planning of AC charging piles based on constraints of time and space. Autom. Electr. Power Syst. 2016, 40, 66-70.

114. Zhen, W. Research on Safety Protection Technology of Electric Vehicle Charging; Nanjing University of Technology: Nanjing, China, 2018. 
115. Yilmaz, M.; Krein, P.T. Review of charging power levels and infrastructure for plug-in electric and hybrid vehicles. In Proceedings of the 2012 IEEE International Electrical Vehicle Conference (IEVC'12), Greenville, SC, USA, 4-8 March 2012; pp. 1-8. [CrossRef]

116. Available online: https://www.sciencedirect.com/science/article/abs/pii/S037877531401489X (accessed on 12 August 2021).

117. Lijun, Q.; Mingyu, Z.; Weiguo, Z. A method to design the security early warning model of EV charging. Power Syst. Clean Energy 2016, 32, 114-119.

118. Wei, G.; Zhengzhe, L. Design and application of isolation self-checking device of charging piles. Hebei Electr. Power 2017, 36, $16-19$.

119. Zhu, L.; Zhang, J. A new model of jointed state of charge and health for lithium batteries. Proc. CSEE 2018, 38, 3613-3621.

120. Hongyu, G.; Jiuchun, J.; Jiapeng, W.; Jiayue, W. New method of insulation detection for electric vehicle. J. Electron. Meas. Instrum. 2011, 25, 253-257.

121. Xiangwen, Z.; Jin, Z.; Yong, X.; Xuanju, D.; Xiru, W.; Taiping, M.; Ming, P.; Fenghua, R. An Online Detection Circuit for Insulation Resistance of Power Battery of Pure Electric Vehicle. CN Patent CN203941235 U, 12 November 2014.

122. Antoun, J.; Kabir, M.E.; Moussa, B.; Atallah, R.; Assi, C. A Detailed Security Assessment of the EV Charging Ecosystem. IEEE Netw. 2020, 34, 200-207. [CrossRef]

123. Lee, S.; Park, Y.; Lim, H.; Shon, T. Study on analysis of security vulnerabilities and countermeasures in ISO /IEC 15118 based electric vehicle charging technology. In Proceedings of the 2014 International Conference on IT Convergence and Security (ICITCS), Beijing, China, 28-30 October 2014; pp. 1-4.

124. Xiang, Z.; Zhihong, L.; Quming, C.; Feng, N.; Hao, Z. Data communication safety Strategy for Electric Vehicle Charging Facilities. Autom. Electr. Power Syst. 2011, 35, 92-94.

125. Bing, Z.; Wei, C.; Feng, Z.; Baofeng, L. Electric vehicle charging pile control device with safety protection function. Low Volt. Electr. Appar. 2013, 16, 53-57.

126. Chang, Y. Research on Comprehensive Evaluation Method for Health Status of Electric Vehicle Charging Point; Harbin University of Science and Technology: Harbin, China, 2020.

127. Han, Z. Research on Health Status Analysis System of Charging Pile Based on Big Data; Xi'an Shiyou University: Xi'an, China, 2019.

128. Yonggang, R.; Zhongdong, Y.; Kai, Z.; Jing, S.; Zhaoan, H.; Liqiang, W. Quantitative assessment of electrical safety protection for electric vehicle charging equipment. J. Electr. Eng. 2017, 12, 25-30, 50. 